\title{
Appendicular Skeleton, Trunk, Skull, and Facial Bones Cancer Pathologic Primary Tumor TNM Finding v8
}

National Cancer Institute

\section{Source}

National Cancer Institute. Appendicular Skeleton, Trunk, Skull, and Facial Bones Cancer Pathologic Primary Tumor TNM Finding v8. NCI Thesaurus. Code C136576.

A pathologic finding about one or more characteristics of appendicular skeleton, trunk, skull, and facial bones cancer, following the rules of the TNM AJCC v8 classification system as they pertain to staging of the primary tumor. 